RAD Conference Proceedings, vol. 3, pp. 73-76, 2018

ISSN 2466-4626 (online) | DOI: 10.21175/RadProc.2018.15

www.rad-proceedings.org

\title{
THE EVALUATION OF THE DOZE RATE FIELD OF INDUSTRIAL X-RAY EQUIPMENT FOR NDT
}

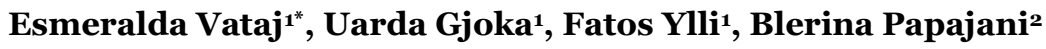 \\ ${ }^{1}$ Institute of Applied Nuclear Physics, University of Tirana, Albania \\ ${ }^{2}$ Aleksander Xhuvani University, Elbasan, Albania
}

\begin{abstract}
Nondestructive Testing (NDT) is a non-invasive method based on physical principles used to evaluate the integrity and characteristics of materials. Its measurement methodology covers a wide range of applications of materials and structures that relate to the entire life cycle, from manufacture to use and retirement. Radiography is one of the most important and widely used NDT methods for volumetric examination. In general, Radiography Testing (RT) is a method of inspecting materials for hidden flaws by using the ability of short wavelength electromagnetic radiation (high energy photons) to penetrate various materials. The intensity of radiation that penetrates and passes through the material is captured by a radiation sensitive film. This study presents the evaluation of the dose rate field in and around the radiation beam for $M H F 200 D X$-ray tube model, using a large interval of voltage (20 to $200 \mathrm{kV}$ ) and current ( 0.5 to $8 \mathrm{~mA}$ ). We controlled the variables that represent the essential characteristics of beam radiation quality, such as voltage $(\mathrm{kV})$, and determined the Half-Value Layer $(\mathrm{HVL})$ for different values of voltage and current.
\end{abstract}

Key words: Dose rate, nondestructive testing, quality control, radiation protection

\section{INTRODUCTION}

Nondestructive Testing (NDT) devices that operate in the field of industrial radiography with X-ray radiation are portable and lightweight devices are adapted to different configurations. NDT systems are designed to reveal defects and are also used for checking assembled parts, the detection of corrosion or other forms of deterioration during maintenance inspections and in research. A periodic quality control of the accuracy of the main physical parameters of NDT devices is required to have a useful ionizing radiation patterns and it is necessary for this control to be in line with the national and international standards, [1], [2], [3], [4], [5].

Industrial radiography ensures the integrity of equipment and structures such as vessels, pipes, welded joints and other devices. The integrity of this equipment affects not only the safety and quality of the products used by workers, but also the safety and quality of the environment for workers and the public at large. Industrial radiography, with high power settings and relatively long exposure times, requires a strict adherence to safety procedures by everyone involved and a periodic personnel exposure check.

Council Directive 2013/59/EURATOM on health protection of individuals against the dangers of ionizing radiation establishes a number of measures to ensure the delivery of exposures under appropriate conditions, with due consideration to quality assurance programs and criteria of acceptability for equipment and installations. The directive also includes requirements regarding the monitoring, evaluation and maintenance of the necessary characteristics of the performance of equipment that can be defined, measured and controlled.

The present publication provides information on the methods that can be used to evaluate the quality control of NDT devices, specifically in industrial radiography. Adherence to the requirements of the quality control tests will: (a) ensure that during normal operation the radiation exposure of both workers and the public is kept as low as reasonably achievable (ALARA principle); (b) ensure that during normal operation the physical parameters of devices and the distribution of the dose rate field fulfill the equipment of Albanian legislation and international standards.

This work has been conducted at the Institute of Applied Nuclear Physics (Tirana, Albania) in order to study the voltage linearity and dose distribution of $\mathrm{X}$-ray machines used in industrial radiography.

\section{Materials AND Methods}

In industrial radiography, the procedure for producing a radiography comprises a strong source of penetrating radiation (X-rays or gamma-rays) on one side of the object to be examined and a detector of radiation (for digital radiography) or a film (for conventional radiography) on the other side. The energy level of radiation must be well chosen so that

*evataj@yahoo.com 
sufficient radiation is transmitted through the object onto the detector.

$\mathrm{X}$-rays can be produced when high energy electrons interact with a material. Inside the $\mathrm{x}$-ray tube, a cathode with a tungsten filament is heated to $2000{ }^{\circ} \mathrm{C}$ and electrons are accelerated by high voltage to interact with an anode target. The kinetic energy of the electrons gives rise to electromagnetic radiation when they hit the target material [6]. The detector is usually a sheet of photographic film, held in a light-tight envelope or cassette having a very thin front surface that allows the X-rays to pass through easily.

MHF $200 D$ device, produced by Gilardoni S.p.A., Italy, uses a large voltage interval of $30 \div 200 \mathrm{kV}$, tube current range of $1 \div 8 \mathrm{~mA}$, maximum power of $900 \mathrm{~W}$, $\mathrm{X}$-ray beam aperture of $40^{\circ} \times 60^{\circ}$, and an inherent filtration of 1.0 mmBe.

MHF 200D portable X-ray machine used in this study is designed for performing directional exposures for radiography tests. The tube assembly is connected by a cable to the control panel, which provides the means for activation and operation of the X-ray equipment, or for the preselection and indication of operating parameters. MHF 200D X-ray machine operates up to $200 \mathrm{kV}$ and is capable of penetrating $42 \mathrm{~mm}$ Fe with the following parameters: density of 2.0, exposure of 10 minutes, FFD of $700 \mathrm{~mm}$, Kodak AA 400 film [7].

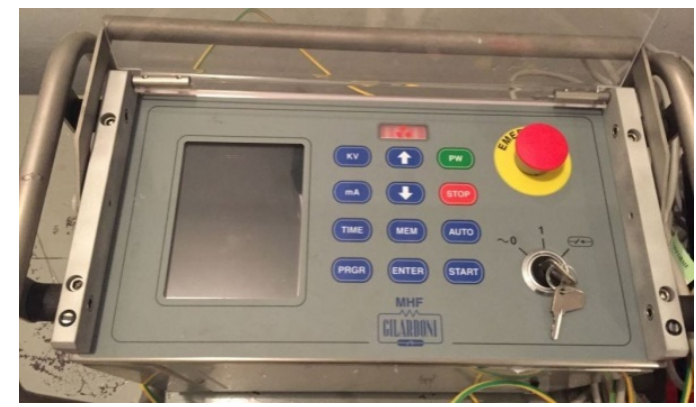

Figure 1. The control panel of MHF 200D X-ray device

For performing the quality control, the multimeter RaySafe Xi is used with the appropriate detector. The RaySafe $\mathrm{Xi}$ is a complete system for multiparameter measurements on all X-ray modalities.

For different applications of dose rate measurements on X-ray machines, the RaySafe $\mathrm{Xi}$ is capable of handling all user scenarios. The RaySafe Xi $\mathrm{R} / \mathrm{F}$ detector is capable of measuring $\mathrm{kVp}$, dose, dose rate, pulse, pulse rate, dose/frame, time, HVL, total filtration and waveforms simultaneously. This is done with minimal user interaction since the instrument has many built-in intelligent solutions, such as automatically detecting and calculating the pulse rate and dose/pulse, or direct HVL measurement for each exposure. The dose measurement range is $10 \mathrm{nGy}-$ 9999 Gy with uncertainty of $5 \%$. The $\mathrm{kV} / \mathrm{kVp}$ measure range is $35-160 \mathrm{kV} / \mathrm{kVp}$ with uncertainty of $2 \%$ (for up to $0.5 \mathrm{mmCu}$ equivalent) and with uncertainty of $3 \%$ (o.5-1mm $\mathrm{Cu}$ equivalent). The HVL measurement range is $1-14 \mathrm{~mm} \mathrm{Al}$ with uncertainty of $10 \%$. The 74 exsposure time measurement range is $1 \mathrm{~ms}-999 \mathrm{~s}$ with uncertainty of $0.5 \%$ or $0.2 \mathrm{~ms}$.

The RaySafe Xi is a solid-state technology and it offers many benefits, including durability, a smaller footprint, and enhanced sensitivity. All RaySafe Xi detectors use multiple sensors and have "Active Compensation" system. This provides flat energy dependence and also enables the measurement of multiple parameters including HVL, all in one instrument.

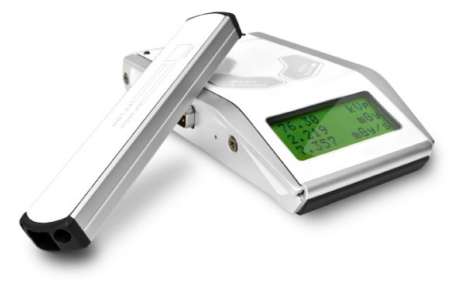

Figure 2. The multimeter RaySafe Xi

\section{RESUlTS AND DisCUSSION}

Minimum performance standards for radiological equipment are established in the EC Radiation Protection Publication No.162 (EU, 2012), [5]. The acceptance criteria specified in the tests described in the following paragraphs are based on the suspension levels recommended by EC and Albanian legislation (2014), [3].

Radiographic devices are designed and constructed to ensure maximum safety and have suitable interlocks, warning lights and signs. With the increased health and safety culture adopted in Albania in recent years, the level of safety awareness of industrial radiographers has improved. The following tests present the new framework on quality control of X-ray devices.

\subsection{Tube voltage accuracy}

The purpose of this measurement is to check the accuracy of the voltage value displayed on the control table. The maximum deviation should be less than $10 \%$ of the measured value.

Table 1 . The accuracy of the voltage value

\begin{tabular}{|c|c|c|c|c|}
\hline Voltage value & \multicolumn{5}{|c|}{ Prescribed value } \\
\hline$[\mathrm{kV}]$ & \multicolumn{3}{|c|}{$\mathrm{D}=80 \mathrm{~cm} \mathrm{I} \mathrm{t}=72.0 \mathrm{~mA}^{*} \mathrm{~s}$} \\
\hline $\mathrm{kV}$ prescribed & 80 & 80 & 80 & Average \\
\hline $\mathrm{kV}$ measurement & 80.33 & 81 & 80.69 & $\mathbf{8 0 . 6 7}$ \\
\hline$\Delta \mathbf{k V}(\%)$ & 0.41 & 1.25 & 0.86 & \\
\hline $\mathrm{kV}$ prescribed & 90 & 90 & 90 & Average \\
\hline $\mathrm{kV}$ measurement & 92.25 & 92.4 & 91.93 & $\mathbf{9 2 . 1 9}$ \\
\hline$\Delta \mathbf{\Delta V}(\%)$ & 2.50 & 2.66 & 2.14 & \\
\hline $\mathrm{kV}$ prescribed & 100 & 100 & 100 & Average \\
\hline $\mathrm{kV}$ measurement & 102.9 & 103 & 102.7 & $\mathbf{1 0 2 . 8 7}$ \\
\hline$\Delta \mathbf{\Delta V}(\%)$ & 2.90 & 3.00 & 2.70 & \\
\hline $\mathrm{kV}$ prescribed & 110 & 110 & 110 & Average \\
\hline $\mathrm{kV}$ measurement & 113.2 & 113.6 & 113.1 & $\mathbf{1 1 3 . 3}$ \\
\hline$\Delta \mathbf{k V}(\%)$ & 2.90 & 3.27 & 2.80 & \\
\hline
\end{tabular}


E. Vataj et al., The evaluation of the doze rate field..., RAD Conf. Proc., vol. 3, 2018, 73-76

The correlation between the average measured value and prescribed value of voltage is shown in the following figure.

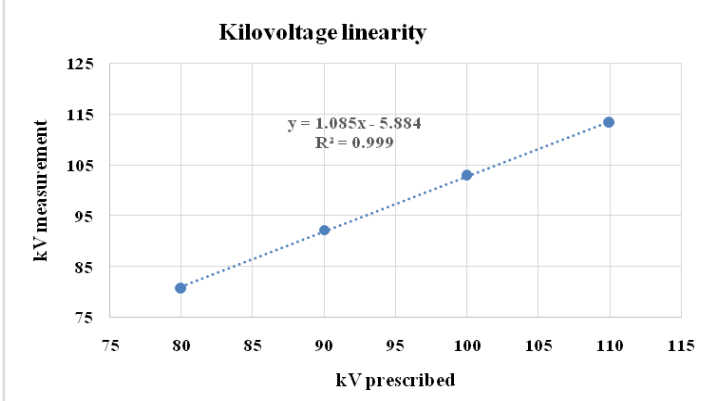

Figure 3. Kilovoltage linearity of MHF 200D X-ray machine

\subsection{Repeatability of output for a fixed setting}

Table 2. The repeatability of the X-tube output - voltage (deviation compared to the average value)

\begin{tabular}{|c|c|c|c|c|c|c|}
\hline \multirow{2}{*}{} & & \multicolumn{5}{|c|}{ Prescribed value } \\
\cline { 3 - 7 } & \multicolumn{4}{|c|}{$\mathrm{U}=8 \mathrm{o} \mathrm{kV}, \mathrm{D}=80 \mathrm{~cm} \mathrm{I} \mathrm{t}=72 \mathrm{mAs}$} \\
\hline $\begin{array}{c}\mathrm{kV} \\
\text { measurement }\end{array}$ & 80.33 & 81 & 80.69 & 81.39 & 81.22 & 81.7 \\
\hline$\Delta \mathrm{kV}(\%)$ & 0.41 & 1.25 & 0.86 & 1.74 & 1.53 & 2.13 \\
\hline
\end{tabular}

* average value $\mathrm{U}_{\text {mes }}=81.05 \mathrm{kV}, \mathrm{STDEV}=0.4934$

The purpose of this measurement is to check the repeatability of the X-tube output, for repeated exposures, at a usual voltage of $80 \mathrm{kV}$. The output should be relatively constant, with a maximum admitted deviation of $\pm 5 \%$ compared with the average value.

\subsection{Consistency or Reliability of output in $k V$ for a range of $m A s$ values}

The purpose of this measurement is to check the magnitude of the variation of the tube output, at a usual working voltage, in case of modification of the product current-time. The value of the output should be relatively constant, with a maximum permitted deviation of $10 \%$.

Table 3. The magnitude of the variation of the tube output for a range of the product current-time

\begin{tabular}{|c|c|c|c|c|}
\hline $\begin{array}{c}\text { Consistency of output } \\
\text { from product I*t }\end{array}$ & \multicolumn{4}{|c|}{ Prescribed value } \\
\hline & $\mathrm{U}=100 \mathrm{kV}, \mathrm{D}=100 \mathrm{~cm} \mathrm{I}=8 \mathrm{~mA}$ \\
\hline $\mathrm{kV}$ measurement & 99.04 & 98.83 & 99.2 & 99.1 \\
\hline mAs prescribed & 120 & 144 & 160 & 200 \\
\hline$\Delta \mathrm{kV}(\%)$ & -0.96 & -1.17 & -0.8 & -0.9 \\
\hline
\end{tabular}

The magnitude of the variation is too low, under permitted deviation, $10 \%$.

\subsection{Magnitude of output $\mu \mathrm{Gy} / \mathrm{mAs}$ at $0.80 \mathrm{~m}$}

The purpose of this measurement is to check the magnitude of the X-ray emission output of the tube. The measurement serves to identify old, aged or defective tubes, which are unfit for further usage.

Table 4 . The repeatability of the X-tube output $-\mu \mathrm{Gy} / \mathrm{mAs}$ at $0.80 \mathrm{~m}$

\begin{tabular}{|c|c|c|c|c|c|c|c|}
\hline X-tube output & & & \multicolumn{5}{|c|}{$\begin{array}{c}\text { Prescribed value } \\
\mathrm{U}=80 \mathrm{kV}, \mathrm{D}=80 \mathrm{~cm} \mathrm{I}=4 \mathrm{~mA}\end{array}$} \\
\hline Dose mGy measurement & 3.87 & 7.19 & 10.59 & 13.91 & 17.37 & 23.95 & average value \\
\hline mAs prescribed & 40 & 60 & 80 & 100 & 120 & 160 & \\
\hline mAs measurement & 25.2 & 45.04 & 65.36 & 85.12 & 105.48 & 145.08 & \\
\hline Calculated $[\mu \mathrm{Gy} / \mathrm{mAs}]$ & 153.57 & 159.55 & 162.03 & 163.42 & 164.68 & 165.08 & 153.57 \\
\hline $\begin{array}{c}\Delta \mathbf{\Delta U} \\
\text { deviation to the average value }\end{array}$ & -0.04 & -0.01 & 0.004 & 0.01 & 0.02 & 0.02 & - \\
\hline
\end{tabular}

*average value $\mathrm{D}_{\text {mes }}=161.39[\mu \mathrm{Gy} / \mathrm{mAs}]$, Filter $2 \mathrm{~mm} \mathrm{Al}+\mathrm{Be}$

\subsection{Distribution of output in $\mu \mathrm{G} y / \mathrm{mAs}$ around focal point}

The distribution of the absorbed dose and dose rate around the axis of the X-ray beam give us the opportunity to have a flat and homogeneous distribution in the whole film surface. The measurement is performed in vertical plan at the distance of $80 \mathrm{~cm}$ from the focus of the X-ray beam with the notation $o$ at the center and 3, 6, 9 and 12 in all places around clockwise.

It is clear from Table 5 that in the whole space related to the film $(48 \mathrm{~cm} x 10 \mathrm{~cm})$ the dose distribution (points 3, o and 9) is roughly uniform and, for the points not belonging to the film area (points 6 and 12), we observe a slight deformation of dose distribution at the distance of $10 \mathrm{~cm}$ and $20 \mathrm{~cm}$ due to the dose and dose rate measurements.
Table 5. The distribution of the absorbed dose in $\mathrm{mGy}$ around the $\mathrm{X}$-tube axis

\begin{tabular}{|c|c|c|c|c|c|}
\hline Detector position & $\mathbf{0}$ & $\mathbf{3}$ & $\mathbf{6}$ & $\mathbf{9}$ & $\mathbf{1 2}$ \\
\hline $\begin{array}{c}\text { Dose mGy measurement } \\
\text { at 10 cm }\end{array}$ & 14.66 & 14.47 & 12.62 & 14.11 & 15.13 \\
\hline $\begin{array}{c}\text { Dose mGy measurement } \\
\text { at 20 cm }\end{array}$ & 14.46 & 13.56 & 8.33 & 13.10 & 14.42 \\
\hline
\end{tabular}

\subsection{Sufficient total filtration}

The purpose of this measurement is to check the value of the fixed total filtration of the useful beam (without additional filters). In case of diaphragms provided with internal filters, which are manually or automatically selectable, the zero value of the filter or its lowest value will be selected. The total filtration should be higher than $2.5 \mathrm{~mm} \mathrm{Al}$. 
E. Vataj et al., The evaluation of the doze rate field..., RAD Conf. Proc., vol. 3, 2018, 73-76

Table 6. The average values of HVL and TF for different measurements

\begin{tabular}{|c|c|c|c|c|c|}
\hline & \multicolumn{5}{|c|}{ Prescribed value } \\
\hline & $\mathrm{U}=100 \mathrm{kV}, \mathrm{D}=100 \mathrm{~cm} \mathrm{I}=8 \mathrm{~mA}$ \\
\hline mAs prescribed & 96 & 120 & 144 & 160 & 200 \\
\hline $\begin{array}{c}\text { average value } \\
\text { HVL(mm Al) }\end{array}$ & 2.87 & 2.98 & 2.98 & 2.98 & 2.99 \\
\hline average value TF & 2.3 & 2.4 & 2.4 & 2.4 & 2.4 \\
\hline
\end{tabular}

*filter: $2 \mathrm{~mm} \mathrm{Al}+\mathrm{Be}$

\section{CONCLUSION}

Quality control tests of NDT X-ray units are undertaken with the purpose of safety and dose optimization in MHF 200D X-ray device model, produced by Gilardoni S.p.A., Italy.

The quality control (QC) programme comprises regular testing that must be carried out on each major component of the system to ensure optimum performance within the system. The equipment testing is coupled with routine environmental monitoring and assessment of the image quality.

From the measurements carried out with the multimeter RaySafe Xi in NDT device model MHF $200 D$, it can be concluded that this device meets the quality control criteria according to the international standards. Quality control is very important for safety procedures in industrial field radiography and also for dosimeteric control and assessment.

In industrial radiography, it is necessary for the quality control to be carried out in accordance with the international protocols, which also serves for the implementation of regulation VKM Nr. 414 (2014), approved by the Albanian Government.

\section{REFERENCE}

1. Radiation protection and safety in industrial radiography, Safety Report Series No. 13, IAEA, Vienna, Austria, 1999.

Retrieved from: https://www-

pub.iaea.org/MTCD/Publications/PDF/Po66 scr.p $\underline{\mathrm{df}} ;$

Retrieved on: Apr. 11, 2018
2. Radiation safety in industrial radiography, Specific Safety Guide No. SSG-11, IAEA, Vienna, Austria. Retrieved from: https://wwwpub.iaea.org/MTCD/Publications/PDF/Pub1466 w eb.pdf; Retrieved on: Apr. 11, 2018

3. $\quad$ Ministria e Shëndetësisë. (18.6.2014). Nr 404 Prot për miratimin e rregullores "për rregullat bazë të instalimeve radiologjike në mjekësi". (Ministra of health. (Jun. 18, 2014). No. 404 on the approval of the regulation "On basic rules of radiological installations in medicine".)

Retrieved from: http://www.ishp.gov.al/wpcontent/uploads/2017/11/Rr.404-dt-18.06.2014Per-rregullat-baze-te-instalimeve-radiologjike-nemjekesi.docx;

Retrieved on: Apr. 11, 2018

4. Safety Procedures for the Installation, Use and Control of X-ray Equipment in Large Medical Radiological Facilities, Safety Code 35, Government of Canada, Ottawa, Canada, 2008.

Retrieved from: https://www.canada.ca/en/healthcanada/services/environmental-workplacehealth/reports-publications/radiation/safety-code35-safety-procedures-installation-use-controlequipment-large-medical-radiological-facilitiessafety-code.html\#ack;

Retrieved on: Apr. 11, 2018

5. Criteria for Acceptability of Medical Radiological Equipment used in Diagnostic Radiology, Nuclear Medicine and Radiotherapy, Radiation Protection $\mathrm{N}^{\circ}$ 162, European Commission, Brussels, Belgium, 2012.

Retrieved from: https://ec.europa.eu/energy/sites/e ner/files/documents/162.pdf;

Retrieved on: Apr. 13, 2018

6. Industrial Radiography, Image forming techniques, General Electric, Boston (MA), USA, 2008.

Retrieved from: https://www.gemeasurement.com/s ites/gemc.dev/files/industrial radiography image forming techniques_english_4.pdf;

Retrieved on: Apr. 13, 2018

7. Gilardoni S.p.A. Instruction for Use of MHF Code 05173201\&05173202 \& O5173211, Z.1666 Rev. 2 07/2004, Gilardoni S.p.A, Milan, Italy, 2004. 